\title{
THE COMPARISON OF AD VALOREM AND SPECIFIC TAXATION UNDER UNCERTAINTY
}

\author{
by \\ Christos Kotsogiannis ${ }^{\dagger}$ and Konstantinos Serfes ${ }^{\ddagger}$
}

October 22,2010

\begin{abstract}
The comparison between specific (per unit) and ad valorem (percentage) taxation has been one of the oldest issues in public finance. In Cournot markets, with deterministic costs structures, conventional wisdom has it that ad valorem taxation welfare-dominates specific. It is shown that in the presence of uncertainty, regarding firms' cost structures, and under reasonable conditions, the conventional wisdom might not hold. The implication of this, from a policy perspective, is that the precise evaluation of the two types of taxation requires an explicit consideration of cost uncertainty.
\end{abstract}

Keywords: Specific taxation; Ad valorem taxation; Comparison of taxes; Imperfect competition; Incomplete information.

JEL classification: H2, L13.

*Acknowledgements: We thank Michael Keen and Markus Reisinger for comments and advice. Any remaining errors are, of course, ours. This research was initiated while Serfes was visiting the University of Exeter Business School and completed while Kotsogiannis was visiting LeBow College of Business, Drexel University. The hospitality of both institutions is gratefully acknowledged.

${ }^{\dagger}$ Department of Economics, University of Exeter Business School, Streatham Court, Rennes Drive, Exeter EX4 4PU, England, UK, and CESIfo, Munich, Germany.

E-mail: c.kotsogiannis@exeter.ac.uk.

${ }^{\ddagger}$ Department of Economics, LeBow College of Business, Drexel University, Philadelphia, PA 19104 US. E-mail: ks346@drexel.edu. 


\section{Introduction}

Two fundamental considerations in the design of fiscal policy, and for the success of fiscal reforms, are the stability, certainty and predictability of tax revenues ${ }^{1}$ and the choice between specific and ad valorem taxes. The interplay between these two considerations - and in particular the role of uncertainty in the comparison of specific and ad valorem taxes - is the focus of this paper.

Uncertainty can arise from various sources but, arguably, a dominant source relates to the volatility (and unpredictability) of firms' input prices, and so their production costs. ${ }^{2}$ To illustrate the role of uncertainty in the welfare-comparison between ad valorem and specific taxation the analysis makes use of the standard Cournot model with incomplete information about own, and also rivals', production costs. This particular information structure introduces two new elements. Firstly, the equilibrium output, and consequently price, follows a distribution. Secondly, while both types of taxation affect the mean of the distribution, only ad valorem taxation affects its dispersion (variance). The consequence of this is that all key welfare measures, which depend on the mean and the dispersion of the output distribution, differ in sign from those obtained from the classical deterministic Cournot model. Arguably, this has important implications, given that uncertainty is an inherent feature of markets, from a policy perspective.

The comparison between specific (per unit) and ad valorem (percentage) taxation has been one of the oldest issues in public finance, going back to Wicksell's $(1896,1959)$ conjecture that ad valorem taxes may have favorable efficiency properties relative to specific taxes in monopoly markets. This conjecture has been formally demonstrated, within a monopoly framework, by Suits and Musgrave (1953). Following the seminal contribution of Suits and Musgrave (1953), a literature has emerged investigating the desirability of one tax over the other under various market structures. ${ }^{3}$ Predominantly, most contributions, with notable exceptions to which we turn below, have focused on deterministic environments.

The results obtained can be summarized as follows. Within the deterministic model, for every specific tax one can find an ad valorem tax that yields the same marginal cost and, hence, the same equilibrium output. This implies that the two taxes are equivalent in terms of social welfare. Since profits under ad valorem are lower than under specific taxation, and consumer surplus is the same, ad valorem taxation generates higher tax revenue, (see, among others,

\footnotetext{
${ }^{1}$ Such issue has been a major concern for many developing countries, Keen (1998).

${ }^{2}$ As in sectors that are energy intensive. Another example of an imperfectly competitive market that is characterized by cost uncertainty is the tobacco industry. Cost uncertainty here can be - and should be-broadly defined to include not only the uncertain quality of tobacco leaves but also the costs associated with regulatory rules and legal threats, World Bank (2003).

${ }^{3}$ Delipalla and Keen (1992), Skeath and Trandel (1994), and Blackorby and Murty (2007) extended Suits and Musgrave (1953) to a homogeneous product symmetric Cournot-Nash oligopoly market. Dierickx et al. (1988), and Denicoló and Matteuzzi (2000) impose asymmetric cost structures. Anderson et al. (2001a,b) allow for differentiated products. Hamilton (2009) extends the analysis to multi-product transactions and Peitz and Reisinger (2009) to vertical oligopolies.
} 
Anderson et al. (2001a,b)). Such conclusion, however, need not hold under cost uncertainty. The driving force behind this possibility is the fact that both consumer surplus and profits are convex in price, thereby making both consumers and firms risk lovers with respect to price. Ad valorem taxation generates higher output (and so price) variability than specific taxation and, therefore, it can lead to higher expected consumer surplus and profits. On the other hand, tax revenue under specific taxation is linear in price, while under ad valorem taxation it is concave in price, thereby making the tax authority risk-averse. Consequently, output and price variability do not affect expected tax revenue under specific taxation, but their impact on expected tax revenue is negative under ad valorem taxation. The implication of this, and contrary to the deterministic model, is that specific taxation can generate higher expected tax revenue than ad valorem. The social welfare equivalence between the two taxes, emphasized in the deterministic model, does not hold. Interestingly, under certain conditions, expected social welfare can even increase in ad valorem taxation.

Contributions $^{4}$ that have attempted to make the link between the comparison of the two types of taxation in an uncertain environment are Fraser (1985), Dickie and Trandel (1996), and Goerke (2008). Like all these contributions, our paper looks at the particular link between the two types of taxation and uncertainty. Unlike Fraser (1985), and Goerke (2008), our focus is not the perfectly competitive environment but the standard Cournot model of output competition. Dickie and Trandel (1996), identify, too, that the equivalence between specific and ad valorem taxes does not hold under uncertainty, but they do so within a model with externalities and mainly under demand uncertainty.

The structure of the paper is as follows. Section 2 introduces the elements of the model. Section 3 describes the equilibrium and derives the equilibrium output and profits, under both types of taxation. Section 4 compares profits and tax revenues under the two taxes. Section 5 deals with consumer and social surplus. Finally, Section 6 briefly concludes.

\section{The structure of the model}

To show that the desirability of one form of tax over the other crucially depends on the information available to firms regarding own and rival costs, this paper analyzes a linearquadratic model with cost uncertainty. This is a tractable model that gives rise to linear conditional expectations that yield closed form solutions and, therefore, a computable (and unique) Bayesian-Nash equilibrium. ${ }^{5}$ It is worth emphasizing - something that will become apparent later on - that the deterministic model (with linear demands) that has been extensively employed in the literature is a special case of the incomplete information model used here.

\footnotetext{
${ }^{4}$ Perloff and $\mathrm{Wu}(2007)$ also emphasize the fact that tax incidence on consumers differ in markets with a price distribution, and so a tax might have an uneven effect on various parts of the price distribution. While this element appears in the model here, too, the framework of Perloff and Wu (2007) bears no resemblance to the framework that is being used here.

${ }^{5}$ See Gal-Or (1987), Li et al. (1987), and Vives (1999) for more details.
} 
The model features two firms that produce a homogenous good. ${ }^{6}$ Market demand is linear in output and given by ${ }^{7}$

$$
p\left(x_{1}+x_{2}\right)=A-\left(x_{1}+x_{2}\right)
$$

where $x_{i}$ denotes the level of output of firm $i=1,2$. Both firms have a linear cost structure with marginal cost $c_{i}$, which in the absence of taxation is given by $c_{i}=\theta_{i} .{ }^{8}$ It is assumed that $\left(\theta_{1}, \theta_{2}\right)$ follow a prior distribution, with the prior marginal density of $\theta_{1}$ and $\theta_{2}$ being identical and equal to $g\left(\theta_{i}\right)$, and $E\left(\theta_{i}\right)=\bar{\theta} \geq 0, \operatorname{Var}\left(\theta_{i}\right)=\sigma, \operatorname{Cov}\left(\theta_{1}, \theta_{2}\right)=h \leq \sigma$, with $h \geq 0$. Each firm receives a signal $s_{i}$ about $\theta_{i}$. The signal $s_{i}$ is an unbiased estimate of the true marginal cost, in the sense that $E\left(s_{i} \mid \theta_{i}\right)=\theta_{i}$ and $E\left[\operatorname{Var}\left(s_{i} \mid \theta_{i}\right)\right]=m$. Conditional on $\theta_{1}$ and $\theta_{2}, s_{1}$ and $s_{2}$ are independently distributed according to the conditional density function $z\left(s_{i} \mid \theta_{i}\right)$. The precision of the signal $s_{i}$ is $1 / m$, whereas the precision of the prior distribution of $\theta_{i}$ is $1 / \sigma$. It is assumed that the posterior density $z(\cdot)$ and the prior density $g(\cdot)$ give rise to the following linear posterior expected values

$$
\begin{aligned}
& E\left(\theta_{i} \mid s_{i}\right)=b+B s_{i}, \quad i=1,2, \\
& E\left(s_{i} \mid s_{j}\right)=f+F s_{i}, \quad i \neq j .
\end{aligned}
$$

Prior-posterior distribution functions that satisfy the linearity assumption in (2) and (3) include the Beta-Binomial, Gamma-Poisson, and Normal-Normal. The following Lemma derives the coefficients of the posterior expectations (all proofs can be found in the Appendices Section).

\section{Lemma 1}

$$
\begin{aligned}
E\left(\theta_{i} \mid s_{i}\right) & =\frac{m}{\sigma+m} \bar{\theta}+\frac{\sigma}{\sigma+m} s_{i}, \quad i=1,2, \\
E\left(s_{j} \mid s_{i}\right) & =\frac{\sigma+m-h}{\sigma+m} \bar{\theta}+\frac{h}{\sigma+m} s_{i}, \quad i \neq j .
\end{aligned}
$$

Lemma 1 simply states that the conditional expectations are a weighted average of the prior mean $\bar{\theta}$ and the signal $s_{i}$. The weights depend on the conditional expected variance of the signal $m$, the prior variance of the cost $\sigma$ and, for equation (5), the covariance between the costs $h$. An example based on the prior-posterior Beta-Binomial distribution functions, and one that we make use of later on, is given below. This distribution function guarantees that the marginal cost is positive for all realizations of uncertainty.

Example (Beta-Binomial). ${ }^{9}$ Suppose that the marginal cost of firm $i$ can be either high $c_{H}$, with probability $\theta_{i}$, or low $c_{L}$, with probability $1-\theta_{i}$. Suppose also that $\theta_{i}$ is distributed on

\footnotetext{
${ }^{6}$ The analysis extends straightforwardly to any fixed number of firms, and to differentiated products, with either Bertrand or Cournot competition but with cost uncertainty. For expositional brevity, the focus here is on the duopoly case with homogeneous products and quantity competition.

${ }^{7}$ The utility function considered is of the form $u(x, y)=A x-x^{2} / 2+y$ with budget constraint $I=p x+y$ (where $x=x_{1}+x_{2}$ and $y$ is the numeraire good). Notice, for later use, that, in this case, consumer surplus (denoted by $C S$ ) is given by $C S=(A-p)^{2} / 2$.

${ }^{8}$ Implicitly in the analysis there is also a deterministic component of the marginal cost which is absorbed by the intercept of the demand $A$.

${ }^{9} \mathrm{An}$ example based on the Gamma-Poisson distribution is available upon request.
} 
$[0,1]$, independently between the two firms, according to a Beta distribution with parameters $\alpha$ and $\beta$. Thus, for any $\theta_{i}$, the expected marginal cost of firm $i$ is given by $c_{H}+\theta_{i} \gamma$, where $\gamma \equiv c_{L}-c_{H}$. Before choosing output $x_{i}$, firm $i$ receives a signal regarding $\theta_{i}$ arising from the average of $n$ independent Bernoulli trials with parameter $\theta_{i} \cdot{ }^{10}$ For simplicity, and without any loss of generality, set $\gamma=1$. It is, thus, the case that the likelihood of the signal $s_{i}$ is $1 / n$ $\operatorname{Binomial}\left(n, \theta_{i}\right)$, with $\operatorname{Var}\left(s_{i} \mid \theta_{i}\right)=\theta_{i}\left(1-\theta_{i}\right) / n$ and $m=E\left[\operatorname{Var}\left(s_{i} \mid \theta_{i}\right)\right]=\left[(\alpha+\beta) \operatorname{Var}\left(\theta_{i}\right)\right] / n$, where $\operatorname{Var}\left(\theta_{i}\right)=\sigma=\alpha \beta /\left[(\alpha+\beta)^{2}(\alpha+\beta+1)\right]$ and, thus, $m=\alpha \beta /[n(\alpha+\beta)(\alpha+\beta+1]$.

Variables pertaining to specific (unit) taxation are denoted by $u$, whereas those pertaining to ad valorem taxation are denoted by $v$. Denoting by $t$ the per unit tax rate, $\lambda$ the ad valorem tax rate, $q$ the producer prices, and $p$ the consumer prices, then

$$
p^{u}=q^{u}+t \quad ; \quad p^{v}=q^{v}(1+\lambda) .
$$

Firm $i$ 's marginal cost of output under specific taxation and ad valorem taxation are given, respectively, by

$$
c_{i}^{u}=\theta_{i}+t \quad ; \quad c_{i}^{v}=\frac{\theta_{i}}{1-\tau},
$$

where $1-\tau=1 /(1+\lambda)$, with $\tau$ being the tax-inclusive rate. Given producer prices and costs, firm $i$ 's profits are given by

$$
\pi_{i}^{u}=\left(p^{u}-c_{i}^{u}\right) x_{i}^{u} \quad ; \quad \pi_{i}^{v}=(1-\tau)\left(p^{v}-c_{i}^{v}\right) x_{i}^{v} .
$$

The comparison between the two taxes requires a common value for one of the fundamental parameters. This, as it is typically the case - see, for instance, Anderson et al. (2001a,b) - is taken to be the unconditional expected marginal cost. Under the two types of taxation, this cost, following $(7)$, is the same if

$$
\frac{\bar{\theta}}{1-\tau}=\bar{\theta}+t
$$

Attention now turns to the analysis of the equilibrium.

\section{Analysis of the equilibrium}

The sequence of events is the following. Given taxes set by the government, nature draws the firms' cost parameters $\left(\theta_{1}, \theta_{2}\right)$, which are unobservable by all economic agents. Then, nature draws the signals $\left(s_{1}, s_{2}\right)$. Firm $i$, upon observing its own signal $s_{i}$, updates its beliefs about cost parameters and chooses non-cooperatively its level of production $x_{i}$. Finally, uncertainty - that is, $\left(\theta_{1}, \theta_{2}\right)$-is realized.

\subsection{Specific taxation}

This model, following Vives (1999), has a unique Bayesian-Nash equilibrium which is linear in the signal a firm receives and is given by

$$
x_{i}=\omega_{i}+\delta_{i} s_{i},
$$

\footnotetext{
${ }^{10}$ For example, the true cost may depend on the outcome of an uncertain R\&D process. If firm $i$ observes $k_{i}$ successes in $n$ trials, the signal is $s_{i}=k_{i} / n$.
} 
where $\omega_{i}$ and $\delta_{i}$ are parameters to be determined (we turn to this shortly below).

Central in the behavior of firm $i=1,2$, are two expectations: The first relates to the expected output of its rival, firm $j \neq i$, conditional on the signal $s_{i}$. This expected output-taking expectations in equation (10) - is given by

$$
E\left(x_{j}^{u}\left(s_{j}\right) \mid s_{i}\right)=\omega_{j}+\delta_{j} E\left(s_{j} \mid s_{i}\right)=\omega_{j}+\delta_{j}\left(\frac{\sigma+m-h}{\sigma+m} \bar{\theta}+\frac{h}{\sigma+m} s_{i}\right),
$$

where the second equality follows from (5). The second expectation relates to firm $i$ 's own expected marginal cost, conditional on its own signal. This cost is given-following upon taking expectations in (7) - by

$$
E\left(c_{i}^{u} \mid s_{i}\right)=E\left(\theta_{i} \mid s_{i}\right)+t=\frac{m}{\sigma+m} \bar{\theta}+\frac{\sigma}{\sigma+m} s_{i}+t,
$$

where the second equality follows from (4).

Firms, given taxes and the signal received, maximize expected profits given by

$$
E\left(\pi_{i}^{u}\left(x_{i}^{u}, x_{j}^{u}\left(s_{j}\right)\right) \mid s_{i}\right)=\left(A-x_{i}^{u}-E\left(x_{j}^{u}\left(s_{j}\right) \mid s_{i}\right)-E\left(c_{i}^{u} \mid s_{i}\right)\right) x_{i}^{u},
$$

with the appropriate choice of $x_{i}^{u}$. It is straightforward to show that the level of output chosen satisfies

$$
x^{u}=\frac{1}{2}\left[A-\omega-\delta\left(\frac{\sigma+m-h}{\sigma+m} \bar{\theta}\right)-\left(\frac{m}{\sigma+m}\right) \bar{\theta}-t-\left(\delta \frac{h}{\sigma+m}+\frac{\sigma}{\sigma+m}\right) s\right] .
$$

(Notice that, due to symmetry, the subscripts $i$ and $j$ are being suppressed.) This choice of output, for any realization of the signal, must be consistent with the hypothesized linear strategies in equation (10). Choosing $\omega$ and $\delta$ in equation (14) to be consistent with the linear strategies hypothesized in equation (10), it is the case that

$$
\omega_{u}=\frac{A-t}{3}-\frac{h+2 m-\sigma}{3(h+2(\sigma+m))} \bar{\theta}
$$

and

$$
\delta_{u}=-\frac{\sigma}{h+2(\sigma+m)},
$$

and, thus, the equilibrium output of the typical firm, denoted by $*$, is given by

$$
x_{u}^{*}=\omega_{u}+\delta_{u} s
$$

Clearly, the typical firm's equilibrium output responds negatively to its own signal. The reason for this is intuitive: If a firm receives, for example, a high signal $s$ it believes, following from (4), that own production costs are high and so it responds, for given rival's output, by reducing the production of own output. Such a response of output depends upon $\operatorname{Var}(\theta)=\sigma, \operatorname{Cov}\left(\theta_{1}, \theta_{2}\right)=$ $h$, and the conditional variance of the signal $E[\operatorname{Var}(s \mid \theta)]=m$. These are key parameters to which we turn to later on. 
Since the cost of production (and the signal received) is a random variable, so will be the production decision of the typical firm, with, in particular, mean and variance. To see this take expectations in equation (17) to arrive at

$$
E\left(x_{u}^{*}\right)=\frac{A-t-\bar{\theta}}{3},
$$

whereas the variance of equilibrium output is given by

$$
\operatorname{Var}\left(x_{u}^{*}\right)=\delta_{u}^{2} \operatorname{Var}(s)=\frac{\sigma^{2}(\sigma+m)}{(h+2(\sigma+m))^{2}},
$$

where the second equality follows from equation (16) and the fact that $\operatorname{Var}(s)=\sigma+m .^{11}$

Equations (18) and (19), and the corresponding for the ad valorem case ones, are central for the intuition underlying the main results. It is clear that specific taxation affects expected output but it does not affect the variance of the output distribution. The reason for this is the additive nature of the specific tax. When a firm receives a high signal $s$ it lowers its output because a high $s$ indicates that the marginal cost $\theta+t$ is high. Nevertheless, the change in the marginal cost, due to a high signal (or equivalently high $\theta$ ), does not depend on $t$, as the specific tax $t$ enters the marginal cost additively. This, too, suggests that the slope of the equilibrium function $\delta_{u}$, given in (16) and which measures the responsiveness of output to the signal a firm receives, does not depend on $t$ and so the variance of output is independent of the level at which the specific tax is set. This, as will be shown shortly below, is not the case under ad valorem taxation.

If there is no uncertainty regarding own production costs, and so $\sigma=0$, then, following from (19), the variance of output is zero, and the model reduces to the standard Cournot duopoly outcome where each firm produces the 'certainty equivalent' level of output given in (18).

Making use now of the equilibrium strategy in (17) into equation (13), expected profits for the typical firm, after some manipulations, can be shown to be

$$
E\left(\pi_{u}^{*}\right)=\left(\frac{A-t-\bar{\theta}}{3}\right)^{2}+\operatorname{Var}\left(x_{u}^{*}\right) .
$$

Equation (20) reconfirms a standard result - see Vives (1999) — and one that will play an important role in the interpretation of the results later on: Firms' profits are convex in their own marginal cost and, thus, they prefer high uncertainty about these costs. ${ }^{12}$

We turn now to ad valorem taxation.

\footnotetext{
${ }^{11}$ This follows from the law of iterated expectations that is, $\operatorname{Var}(s)=\operatorname{Var}[E(s \mid \theta)]+E_{\theta}[\operatorname{Var}(s \mid \theta)]=$ $\sigma+m$.

${ }^{12} \mathrm{Or}$, to put it differently, firms exhibit risk loving behavior.
} 


\subsection{Ad valorem taxation}

The details for ad valorem taxation are similar to those under specific taxation, and in order to avoid repetition they are omitted. It suffices here, however, to state that the typical firm's equilibrium output strategy is

$$
x_{v}^{*}=\omega_{v}+\delta_{v} s,
$$

where

$$
\omega_{v}=\frac{A}{3}-\frac{(h+2 m-\sigma) \bar{\theta}}{3(1-\tau)(h+2(\sigma+m))},
$$

and

$$
\delta_{v}=-\frac{1}{(1-\tau)} \frac{\sigma}{h+2(\sigma+m)} .
$$

A firm's output is, then, distributed with mean

$$
E\left(x_{v}^{*}\right)=\frac{A}{3}-\frac{\bar{\theta}}{3(1-\tau)},
$$

and variance

$$
\operatorname{Var}\left(x_{v}^{*}\right)=\delta_{v}^{2} \operatorname{Var}(s)=\frac{1}{(1-\tau)^{2}} \frac{\sigma^{2}(\sigma+m)}{(h+2(\sigma+m))^{2}},
$$

where, again, $\operatorname{Var}(s)=\sigma+m$. As in the case of specific taxation, when there is no uncertainty regarding own production costs, the equilibrium reduces to the standard Cournot outcome, where each firm produces the level of output given in equation (24). With uncertainty, higher signal implies lower output. The most crucial difference with specific taxation is that ad valorem taxation affects not only the mean of the distribution but also the variance (as can be seen from (25)). This is because the change in the marginal cost $\theta /(1-\tau)$ when $s$ changes does depend on $\tau$, simply because ad valorem taxation, unlike specific, enters in a nonadditive way. This dependence affects the slope $\delta_{v}$ of the typical firm's equilibrium output response to own signal and, consequently, the variance of output. Close inspection of the typical firm's equilibrium output response to own signal under the two types of taxation reveals that - for any ad valorem tax rate $\tau$ and for given signal $s$-ad valorem taxation gives rise to a more responsive output than specific taxation. To see this, it is easy to verify - following from (16) and (23) - that

$$
\delta_{v}=\frac{1}{1-\tau} \delta_{u}
$$

and so for any given signal $s$, and for $\tau<1, \partial x_{v}^{*} / \partial s=\delta_{v}>\partial x_{u}^{*} / \partial s=\delta_{u}$. This in turn implies, following from (19) and (25), that the variance of output under ad valorem taxation is higher than the variance of output under specific taxation. To emphasize:

Proposition 1 (Higher output variance under ad valorem) The variance of output under ad valorem taxation, all other things being equal, is higher than under specific.

It is also straightforward to verify, following from (15) and (22), that when expected effective costs are the same (and so equation (9) holds), expected output is the same under both ad valorem and specific taxation, and equal to

$$
\omega_{u}=\omega_{v}=\frac{A}{3}-\frac{\bar{\theta}}{3(1-\tau)},
$$


and so will be expected prices. This will be the basis of comparison for the two types of taxation.

Notice, to complete the description, the typical firm's expected profits are given by

$$
E\left(\pi_{v}^{*}\right)=(1-\tau)\left[\left(\frac{A(1-\tau)-\bar{\theta}}{3(1-\tau)}\right)^{2}+\operatorname{Var}\left(x_{v}^{*}\right)\right]
$$

and, thus, in this case, too, expected profits depend positively on output variability.

\section{Profit and tax revenue comparison}

In the deterministic Cournot model ad valorem taxation, compared to specific, is associated with lower profits and, therefore, higher tax revenue; a point emphasized in, among others, Delipalla and Keen (1992), and Anderson et al. (2001a,b). Such comparisons, however-and this is an issue at the heart of this paper-fail to hold when production cost is not deterministic. We turn to this next, starting from the comparison of profits.

\subsection{Profits}

The difference in expected profits under the two types of taxation, for any $t$ and $\tau$ and evaluated at the same effective cost using (9), is given - following from (19), (20), (25), and (28) - by

$$
E\left(\pi_{v}^{*}\right)-E\left(\pi_{u}^{*}\right)=-\frac{\tau(A(1-\tau)-\bar{\theta})^{2}}{9(1-\tau)^{2}}+\frac{\tau}{(1-\tau)} \frac{\sigma^{2}(\sigma+m)}{(h+2(\sigma+m))^{2}} .
$$

It is, thus, the case that the balance of the comparison between ad valorem and specific taxation depends on the two terms on the right-hand-side of (29): The first one reflects the difference in profits when the variance of output $\sigma$ is zero. The second term, captures the difference in profits when taxation (ad valorem and specific) affects the output and price distributions. Clearly, the first term is negative and, thus, points to a dominant (in terms of profits generated) specific taxation. The sign of the second term is positive and points towards a dominant ad valorem (in terms of profits generated) tax. Interestingly, the latter term dominates the former if the variance of output $\sigma$ is sufficiently high. To emphasize: ${ }^{13}$

Proposition 2 (Profits comparison) If, all other things being equal, the variance of output is sufficiently high, (expected) profits are higher under ad valorem than specific taxation.

Proposition 2 emphasizes that, contrary to the deterministic models, profits can be higher under ad valorem taxation when the variance of output is sufficiently high. The intuition for this comparison is as follows. As we alluded to previously, profits are convex in the marginal cost and so the signals firms receive. This implies that the loss of profits when the signal is

\footnotetext{
${ }^{13}$ It is not difficult to find examples for which this holds. Suppose, to see such possibility, that costs (between firms) are uncorrelated and so $h=0$. In this case, equation (29) is strictly positive if $\sigma^{2} /(4(\sigma+m))>(A(1-\tau)-\bar{\theta})^{2} /(9(1-\tau))$. Clearly, given that the right-hand-side of the latter condition is independent of the variance parameters $\sigma$ and $m$, one can find parameter values such that the above inequality holds.
} 
high (and, hence, the marginal cost is high) is less than the gain when the signal is low. As a result, higher variance increases expected profits. Since, as showed earlier, only ad valorem taxation affects the variance of output, it is the ad valorem tax that generates higher variance and makes higher expected profits possible, even when the two taxes yield the same expected marginal cost. We turn now to the comparison of tax revenues.

\subsection{Tax revenues}

Expected tax revenues differ under both types of tax. The difference hinges upon the way the signals (a noisy proxy for marginal costs) received by firms affect revenues. Under specific taxation tax revenues are linear in the signals. Therefore, expected tax revenues do not depend on the variance of output, as it is indeed shown below (evaluated at equal effective costs using (9))

$$
E\left(r_{u}^{*}\right)=\frac{2 \bar{\theta} \tau}{3(1-\tau)^{2}}[A(1-\tau)-\bar{\theta}] .
$$

Under ad valorem taxation a lower signal raises output, but decreases consumer price $p^{v}$ and, consequently, producer price $q^{v}$. The consequence of this is that tax revenues are concave in the signals. The implication of this is that the tax authority, under ad valorem taxation, becomes risk averse, and, therefore, higher variance lowers expected revenues. This latter observation can be seen from the expected tax revenues under ad valorem taxation

$$
E\left(r_{v}^{*}\right)=\frac{2 \tau(A(1-\tau)+2 \bar{\theta})(A(1-\tau)-\bar{\theta})}{9(1-\tau)^{2}}-\frac{2 \tau \sigma^{2}}{(1-\tau)^{2}} \frac{h+\sigma+m}{(h+2(\sigma+m))^{2}},
$$

which is decreasing in the variance (that appears in the second term on the right-hand-side). If the variance $\sigma$ is zero and the effective cost is the same, then, ad valorem dominates in terms of tax revenues. Indeed, setting $\sigma=0$ and taking the difference between tax revenue under the two types of taxation, making use of (30) and (31), one arrives at $E\left(r_{v}^{*}\right)-E\left(r_{u}^{*}\right)=$ $2 \tau(A(1-\tau)-\bar{\theta})^{2} /\left(9(1-\tau)^{2}\right)>0$. This confirms the result in Anderson et al. (2001a).

Interestingly, however, the dominance of ad valorem taxation might not hold in the presence of cost uncertainty. Comparing expected total revenues in this case we have that

$$
E\left(r_{v}^{*}\right)-E\left(r_{u}^{*}\right)=\frac{2 \tau}{(1-\tau)^{2}}\left[\frac{(A(1-\tau)-\bar{\theta})^{2}}{9}-\frac{\sigma^{2}(\sigma+m+h)}{(h+2(\sigma+m))^{2}}\right] .
$$

Close inspection of equation (32) reveals that specific taxation is more likely to generate higher expected revenues if the variance $\sigma$ is high enough. To demonstrate the possibility that specific taxation revenue-dominates ad valorem, consider the Beta-Binomial example introduced earlier. Assume also that the marginal cost $\theta$ is distributed according to a Beta distribution with parameters $\alpha=1 / 2$ and $\beta=1$, that the intercept of demand is $A=3 / 2$, and that $h=(1 / 2) \sigma$ (with $n=10$ ). Figure 1 depicts expected tax revenue when the variance $\sigma=0$ (left panel) and when $\sigma>0$ according to the Beta-Binomial parameters (right panel). When the variance $\sigma=0$, ad valorem taxation (dashed curve) revenue-dominates specific taxation (solid curve), but with variance $\sigma>0$ the reverse can be true. The consequence of this is that, interestingly, in an uncertain environment, there exists high enough (expected) tax revenue targets that can only be attained with specific taxation. To summarize the preceding discussion: 

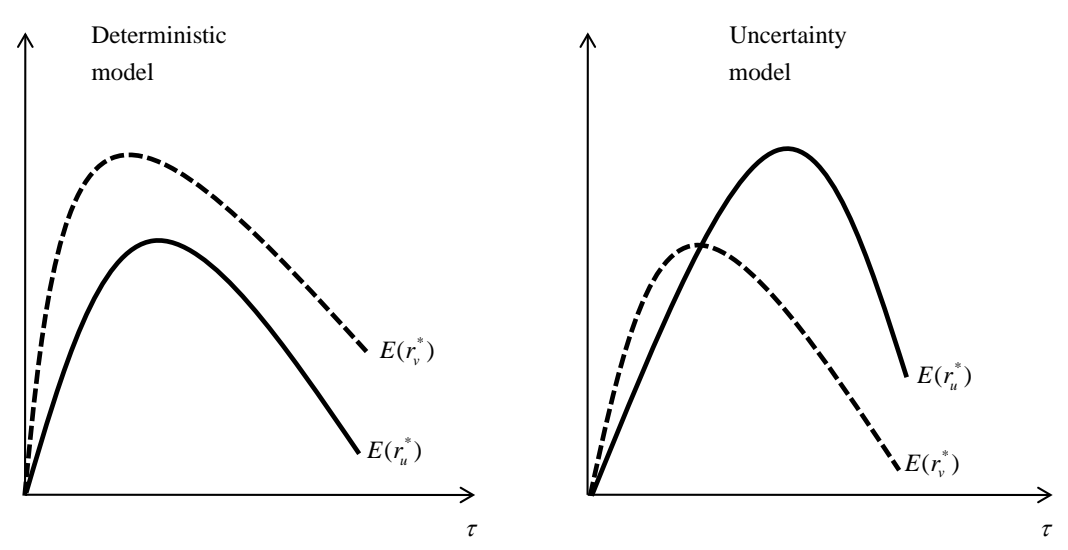

Figure 1: Expected tax revenues, Beta-Binomial

Proposition 3 (Tax revenue comparison) If, all other things being equal, the variance of output is sufficiently high, (expected) tax revenue under specific taxation yields higher tax revenues than ad valorem taxation.

We now turn to consumer and social surplus.

\section{Comparison of consumer and social surplus}

\subsection{Consumer surplus}

For any realizations of the signals $\left(s_{1}, s_{2}\right)$, expected consumer surplus under specific taxation is given by ${ }^{14}$

$$
E\left(C S_{u}^{*}\right)=\frac{2(A-\bar{\theta}-t)^{2}}{9}+\frac{\sigma^{2}(h+\sigma+m)}{(h+2(\sigma+m))^{2}},
$$

and

$$
E\left(C S_{v}^{*}\right)=\frac{2(A(1-\tau)-\bar{\theta})^{2}}{9(1-\tau)^{2}}+\frac{1}{(1-\tau)^{2}} \frac{\sigma^{2}(h+\sigma+m)}{(h+2(\sigma+m))^{2}},
$$

under ad valorem taxation. Clearly, if the variance $\sigma=0$ and expected effective cost is the same under both taxes, then, $E\left(C S_{u}^{*}\right)=E\left(C S_{v}^{*}\right)$. This, however, does not hold in the presence even of a small degree of uncertainty. In this case ad valorem taxation yields higher consumer surplus than specific. To emphasize:

Proposition 4 (Consumer surplus comparison) Expected consumer surplus under ad valorem taxation, all other things being equal, is strictly higher than that under specific taxation, for any positive level of variance $\sigma$.

The intuition behind Proposition 4 is that consumers like price variability and ad valorem taxation does precisely this; it generates higher price (output) variance than specific taxation.

\footnotetext{
${ }^{14}$ The derivations are tedious and are, for brevity, omitted.
} 
Furthermore, ad valorem taxation can even increase expected consumer surplus. To see this, differentiate equation (34) with respect to $\tau$ and evaluate the derivative at $\tau=0$ to obtain

$$
\frac{d E\left(C S_{u}^{*}\right)}{d \tau}=-\frac{4 \bar{\theta}(1-\bar{\theta})}{9}+\frac{2(h+\sigma+m) \sigma^{2}}{(h+2(\sigma+m))^{2}} .
$$

The first term in the right-hand-side of (35) is negative, pointing to the adverse effect of taxation on consumer welfare (a consequence, as emphasized earlier, of a high expected price). The second term, however, is positive pointing to the beneficial effect of taxation on consumer welfare (a consequence of price variability). It is, thus, the case that for high enough variance, the second term dominates the first, suggesting that higher ad valorem taxation can increase expected consumer surplus, at least for low $\tau$. Specific taxation, on the other hand, always affects expected consumer surplus negatively. The reason for this is intuitive: Price variability is independent of the specific tax and, hence, the second term in (35) vanishes. This will also hold next when we examine the effects of the two types of taxes on social surplus.

The above analysis begins to suggest that ad valorem may dominate specific when it comes to social surplus. We turn to this next.

\subsection{Social surplus}

The two taxes are not equivalent in terms of expected social surplus. More importantly, ad valorem taxation can even increase expected social surplus when the variance of output is strong enough. Expected social surplus is the sum of expected consumer surplus, expected profits and expected revenues. Expected social surplus under specific taxation is given-making use of (20), (30), and (33)-by

$$
S S_{u}^{*}=\frac{2(2(A-\bar{\theta})+t)(A-\bar{\theta}-t)}{9}+\frac{\sigma^{2}(h+3(\sigma+m))}{(h+2(\sigma+m))^{2}},
$$

whereas - making use of (28), (31), and (34) - expected social surplus under ad valorem taxation is given by

$$
S S_{v}^{*}=\frac{2(A(1-\tau)-\bar{\theta})(2 A(1-\tau)-(2-3 \tau) \bar{\theta})}{9(1-\tau)^{2}}+\frac{(h+3(\sigma+m)-2 \tau(h+2(\sigma+m))) \sigma^{2}}{(1-\tau)^{2}(h+2(\sigma+m))^{2}} .
$$

The expected social surplus under specific taxation when evaluated at same expected effective costs, following from equation (9), becomes

$$
S S_{u}^{*}=\frac{2(A(1-\tau)-\bar{\theta})(2 A(1-\tau)-(2-3 \tau) \bar{\theta})}{9(1-\tau)^{2}}+\frac{\sigma^{2}(h+3(\sigma+m))}{(h+2(\sigma+m))^{2}} .
$$

It is clear that if the variance $\sigma=0$, then, the second term both in (37) and (38) vanish, leaving $S S_{u}^{*}=S S_{v}^{*}$. This reconfirms the point made by Anderson et al. (2001a). The intuition here is the same as the one offered in Anderson et al. (2001a): With effective costs being the same output is the same under both ad valorem and specific taxation and so is the price.

The difference in the expected social surplus between the two taxes is given by

$$
S S_{v}^{*}-S S_{u}^{*}=\frac{(2(m+\sigma)-\tau(h+3(\sigma+m))) \sigma^{2} \tau}{(1-\tau)^{2}(h+2(\sigma+m))^{2}} .
$$


It can be shown that this difference is concave in $\tau$ achieving a maximum at $\tau=(\sigma+m) /(h+3 m+3 \sigma)<$ 1. It is also the case that for $\tau \in(0,2(\sigma+m) /(h+3 m+3 \sigma))$ the difference is positive, whereas for $\tau>2(\sigma+m) /(h+3 m+3 \sigma)$ the difference is negative.

An increase in specific taxation $t$-where $t$ changes according to $\bar{\theta}+t=\bar{\theta} /(1-\tau)$, and for $\tau \leq 1$-lowers expected social surplus in the sense that

$$
\frac{\partial S S_{u}^{*}}{\partial \tau}=-\frac{2(A(1-\tau)-\bar{\theta}(1-3 \tau)) \bar{\theta}}{9(1-\tau)^{3}} \leq 0 .
$$

Interestingly, this might not be the case under ad valorem taxation. To see this, differentiate (37) with respect to $\tau$, and evaluate the derivative at $\tau=0$, to obtain

$$
\frac{\partial S S_{v}^{*}}{\partial \tau}=-\frac{2(A-\bar{\theta}) \bar{\theta}}{9}+\frac{2 \sigma^{2}(\sigma+m)}{(h+2(\sigma+m))^{2}} .
$$

Inspection of (41) reveals that for high enough variance $\sigma$ a tax increase leads to higher (expected) social surplus. The reason for this, unlike specific taxation, is that, as noted earlier, ad valorem taxation affects the variance and as a consequence an increase in the tax has two effects on expected social welfare. On the one hand, expected marginal cost increases which lowers welfare, but, on the other hand, the increase in variance increases welfare. It is plausible - and indeed this is the case - that for high levels of variance $\sigma$ the second effect may dominate. To summarize the preceding discussion:

Proposition 5 (Social surplus) Expected social surplus is decreasing in the specific tax $t$. However, expected social surplus under ad valorem taxation is increasing in the ad valorem tax $\tau$, for low levels of $\tau$, provided that the variance of output is high enough. In particular, it is inverse $U$-shaped in $\tau$. When the output variance is low, then expected social surplus under ad valorem is decreasing in $\tau$.

The intuition behind Proposition 5 follows from the responses of the individual components of the expected social surplus with respect to variance $\sigma$. Under specific taxation expected profits and expected consumer surplus depend positively on the variance, while expected tax revenue is independent of the variance. Under ad valorem taxation, on the other hand, expected tax revenue depends negatively on the variance. For low levels of $\tau$ ad valorem yields higher expected social surplus because it generates higher variance, but for high levels of $\tau$ the negative effect of variance on expected tax revenue dominates and specific taxation is more efficient.

\section{Concluding remarks}

The analysis has focused on the explicit comparison of all key welfare measures under ad valorem and specific taxation. It has been shown that, contrary to the deterministic model, specific taxation might dominate ad valorem in terms of tax revenues, while ad valorem taxation might dominate in terms of profits and consumer surplus. While the two taxes yield the same social welfare in a deterministic model (a special case of the model considered here), this is not the case under uncertainty. Interestingly, social surplus can even increase in the ad valorem tax. 
A question that, naturally, arises is which tax dominates if the government solves the Ramsey problem, in the sense that it wishes to maximize consumer welfare (consumer surplus plus profits) subject to some given tax revenue requirement. Unfortunately, while it is easy to demonstrate - as the analytics here have shown - the possibility that, compared to the deterministic model, all key welfare measures change sign in the presence of uncertainty, obtaining an easily interpretable solution for the Ramsey problem that shows the possibility that specific taxation can dominate ad valorem taxation has not been possible. This does not, of course, imply that such possibility does not exist. It does, however, begin to suggest that the model being used might not be sufficiently flexible to address the analytical complexity of the problem.

We hope to have shown that the results obtained are instructive and could serve as stepping stones to future explorations of the comparison between ad valorem and specific taxation under uncertainty in more general settings. 


\section{References}

[1] Anderson, S., A. de Palma, and B. Kreider. (2001a). The efficiency of indirect taxes under imperfect competition. Journal of Public Economics 81, 231-251.

[2] Anderson, S., A. de Palma, and B. Kreider. (2001b). Tax incidence in differentiated product oligopoly. Journal of Public Economics 81, 173-192.

[3] Blackorby, C., and S. Murty. (2007). Unit versus ad valorem taxes : Monopoly in general equilibrium. Journal of Public Economics 91, 817-822.

[4] Delipalla, S., and M. J. Keen. (1992). The comparison between ad valorem and specific taxation under imperfect competition. Journal of Public Economics 49, 351-361.

[5] Denicoló, V., and M. Matteuzzi. (2000). Specific and ad valorem taxation in asymmetric Cournot oligopolies. International Tax and Public Finance 7, 335-342.

[6] Dickie, M., and G. Trandel. (1996). Comparing specific and ad valorem Pigouvian taxes and output quotas. Southern Economic Journal 63, 388-405.

[7] Dierickx, I., C. Matutes, and D. Neven. (1988). Indirect taxation and Cournot equilibrium. International Journal of Industrial Organization 6, 385399.

[8] Erikson, W.A. (1969). A note on the posterior of a population mean. J. R. Statist. Soc. B, 31, 332-334.

[9] Fraser, R.W. (1985). Commodity taxes under uncertainty. Journal of Public Economics $28,127-134$.

[10] Gal-Or, E. (1987). First mover disadvantages with private information. Review of Economic Studies 54, 279-292.

[11] Goerke, L. (2008). Commodity tax structure under uncertainty in a perfecty competitive market. Mimeo, Eberhard Karls Universität Tübingen.

[12] Hamilton, S. (2009). Excise taxes with multiproduct transactions. American Economic Review 99, 458-471.

[13] Keen, M. (1998). The balance between specific and ad valorem taxation. Fiscal Studies 19, 1-37.

[14] Li, L., R.D. McKelvey, and T. Page. (1987). Optimal research for Cournot oligopolists. Journal of Economic Theory 42, 140-166.

[15] Peitz, M., and M. Reisinger. (2009). Indirect taxation in vertical oligopoly. CESIfo Working paper.

[16] Perloff, J.M., and X. Wu. (2007). Tax incidence varies across the price distribution. Economics Letters 96, 116-119.

[17] Suites, D., and R. Musgrave. (1953). Ad valorem and unit taxes compared. Quarterly Journal of Economics 67, 598-604.

[18] Skeath, S., and G. Trandel. (1994). A Pareto comparison of ad valorem and unit taxes in noncompetitive environments. Journal of Public Economics 53, 53-71. 
[19] Vives, X. (1999). Oligopoly pricing: Old ideas and new tools. Cambridge, MA: MIT Press.

[20] Wicksell, K. (1896). Taxation in the monopoly case. In Readings in the Economics of Taxation, ed. R. Musgrave and C. Shoup, 156-177. Irwin, OH: Homewood Press, 1959.

[21] World Bank. (2003). The economics of tobacco use and tobacco control in the developed world. 


\section{Appendices}

\section{Proof of Lemma 1.}

Given the linearity of the posterior expectations, following Erickson (1969), it is the case that

$$
E\left(\theta_{i} \mid s_{i}\right)=\left(\frac{R}{R+r}\right) E\left(\theta_{i}\right)+\frac{r}{R+r} s_{i}
$$

where $r=1 / E\left(\operatorname{Var}\left(s_{i} \mid \theta_{i}\right)\right)$ and $R=1 / \operatorname{Var}\left(\theta_{i}\right)$.

Since $E\left(\operatorname{Var}\left(s_{i} \mid \theta_{i}\right)\right)=m, \operatorname{Var}\left(\theta_{i}\right)=\sigma$ and $E\left(\theta_{i}\right)=\bar{\theta}$, it follows from (A.1) that

$$
E\left(\theta_{i} \mid s_{i}\right)=\frac{m}{\sigma+m} \bar{\theta}+\frac{\sigma}{\sigma+m} s_{i}, \quad i=1,2 .
$$

Following from the linear posterior expected values given in equations (2) and (3), it is the case that

$$
\begin{aligned}
E\left(s_{1} s_{2}\right) & =E E\left(s_{1} s_{2} \mid s_{1}\right)=E\left(s_{1} E\left(s_{2} \mid s_{1}\right)\right)=E\left(s_{1}\left[d+D s_{1}\right]\right) \\
& =d E\left(s_{1}\right)+D E\left(s_{1}^{2}\right) \\
E\left(s_{2}\right) & =E E\left(s_{2} \mid s_{1}\right)=d+D E\left(s_{1}\right) .
\end{aligned}
$$

Since

$$
\begin{aligned}
E\left(s_{1} s_{2}\right) & =h+\bar{\theta}^{2}, \\
E\left(s_{1}^{2}\right) & =\sigma+m+\bar{\theta}^{2}, \\
E\left(s_{1}\right) & =\bar{\theta}
\end{aligned}
$$

solving now for the parameters (simultaneously) one obtains (for $i \neq j$ )

$$
E\left(s_{i} \mid s_{j}\right)=\frac{\sigma+m-h}{\sigma+m} \bar{\theta}+\frac{h}{\sigma+m} s_{i},
$$

as required.

Below, we offer the steps taken for the derivation of the expected revenues under both taxes. Since the derivations of the other welfare measures follow analogous steps, they are omitted for brevity.

\section{B.1 Derivation of equation (30).}

Under specific taxation, revenues are given by

$$
r^{u}=t \sum x_{u i}^{*}
$$

which upon using the definition of equilibrium output (10) it becomes

$$
r_{u}^{*}=t\left(2 \omega_{u}+\delta_{u} \sum s_{i}\right) .
$$


Substituting the equilibrium definitions of $\omega_{u}$, following from (15), and the fact that

$$
t=\frac{\bar{\theta} \tau}{1-\tau}
$$

it is the case that

$$
r_{u}^{*}=\frac{2 \bar{\theta} \tau}{1-\tau}\left[\frac{A(1-\tau)-\bar{\theta} \tau}{3(1-\tau)}-\frac{\bar{\theta}}{3} \frac{2 m+h-\sigma}{h+2(\sigma+m)}+\frac{\delta_{u}}{2} \sum s_{i}\right] .
$$

Taking expectations - making use of the fact that $E\left(s_{i} \mid \theta_{i}\right)=\bar{\theta}$ but also the equilibrium definition of $\delta_{u}$ from (16) - and after some straightforward manipulations, ones obtains

$$
E\left(r_{u}^{*}\right)=\frac{2 \bar{\theta} \tau}{3(1-\tau)^{2}}[A(1-\tau)-\bar{\theta}]
$$

as required.

\section{C.1 Derivation of equation (31).}

Under ad valorem taxation, tax revenues are given by

$$
\begin{aligned}
r_{v}^{*} & =q^{v} \lambda \sum x_{v i}^{*}, \\
& =\frac{\lambda}{1+\lambda}\left(A-\sum x_{v i}^{*}\right) \sum x_{v i}^{*},
\end{aligned}
$$

where the second equality follows from (6) and the definition of $p^{v}$ in (1). Substituting the definition of equilibrium output given in (21), and using the fact that $1-\tau=1 /(1+\lambda),(\mathrm{C} .2)$ becomes

$$
r^{v}=\tau\left(a-\delta_{v} \sum s_{i}\right)\left(b+\delta_{v} \sum s_{i}\right),
$$

where $a \equiv A-2 \omega_{v}$ and $b \equiv 2 \omega_{v}$. Taking expectations in (C.3) it is the case that

$$
\begin{aligned}
E\left(r_{v}^{*}\right) & =\tau\left\{a b+(a-b) \delta_{v} E\left(\sum s_{i}\right)-\delta_{v}^{2} E\left[\left(\sum s_{i}\right)^{2}\right]\right\} \\
& =\tau\left\{a b+2(a-b) \delta_{v} \bar{\theta}-\delta_{v}^{2} E\left[\left(\sum s_{i}\right)^{2}\right]\right\}
\end{aligned}
$$

where the second equality follows from the fact that $E\left(\sum s_{i}\right)=2 \bar{\theta}$. Following from the proof of Lemma 1 and, in particular (A.6) and (A.7), it is also the case that

$$
E\left[\left(\sum s_{i}\right)^{2}\right]=v+h+4 \bar{\theta}^{2}
$$

where

$$
v \equiv h+2(\sigma+m) .
$$

Following now from (C.7), (22) and (23) can be written, respectively, as

$$
\omega_{v}=\frac{1}{3}\left(A-\frac{(v-3 \sigma) \bar{\theta}}{(1-\tau) v}\right) \quad ; \quad \delta_{v}=-\frac{1}{(1-\tau)} \frac{\sigma}{v} .
$$

It is straightforward now to verify that

$$
a b+2(a-b) \delta_{v} \bar{\theta}=\frac{2(A(1-\tau)+2 \bar{\theta})(A(1-\tau)-\bar{\theta})}{9(1-\tau)^{2}}+\frac{4 \bar{\theta}^{2} \sigma^{2}}{(1-\tau)^{2} v^{2}},
$$


and

$$
\delta_{v}^{2} E\left[\left(\sum s_{i}\right)^{2}\right]=\frac{\sigma^{2}\left(v+h+4 \bar{\theta}^{2}\right)}{(1-\tau)^{2} v^{2}} .
$$

Substituting now (C.9) and (C.10) into (C.5) - and upon using the definition in (C.7) - one arrives at

$$
E\left(r_{v}^{*}\right)=\frac{2 \tau(A(1-\tau)+2 \bar{\theta})(A(1-\tau)-\bar{\theta})}{9(1-\tau)^{2}}-\frac{2 \tau \sigma^{2}}{(1-\tau)^{2}} \frac{h+\sigma+m}{(h+2(\sigma+m))^{2}},
$$

as required. 